\title{
Ivo Andrić und seine Bedeutung für die serbische Sprache
}

КУСТУРИЦА, Е., КОВАЧЕВИЋ, М. (ур.): Значај срйской језика за очување срйской културноі ияентитета. I: Иво Анgрић и срйски језик. Радови са научног скупа одржаног у Андрићграду 12-13. маја 2018. (= Одјељење за српски језик. Библиотека Научни скупови; књига 1). Вишеград (Андрићград): Андрићев институт, 2018. 489 стр.

Im vorliegenden Sammelband werden auf 489 Seiten Arbeiten zu Ivo Andrić, seinem facettenreichen Werk und seinem Einfluss auf die serbische Sprache und Kultur vorgestellt. Philologen aus Bosnien-Herzegowina, Serbien und Bulgarien legen Einzelstudien vor, die sowohl vor dem Hintergrund sprachwissenschaftlicher, literaturwissenschaftlicher sowie kulturhistorischer Aspekte reflektiert und fundiert ausgewertet werden.

$\mathrm{Zu}$ Beginn hinterfragt Miloš M. Kovačević Andrićs Perspektive auf Sprache und Stilistik, die der Autor selbst niemals zum zentralen Gegenstand einer seiner Texte machte, die er aber dennoch in seinen Ausführungen zu Vuk Karadžić durchblicken lässt. ${ }^{1}$ Vor allem der gute Stil steht hier im Vordergrund, er könne nur dann erkannt werden, wenn Ausdruck und Inhalt einer Aussage harmonieren. ${ }^{2}$ Dragan B. Bošković beleuchtet das nihilistische Schicksal des Zeichens in Andrićs Prosa und interpretiert (eigentlich konventionelle) Zeichen als semiologische Bruchstellen. Sie korrespondieren in gewisser Weise mit den gebrochenen Biographien einiger Protagonisten. ${ }^{3}$ In den Betrachtungen von Biljana S. Samardžić, die die serbische Sprache als Kohäsionsfaktor im Aufeinandertreffen der Zivilisationen sieht, bekommt der Leser einen interessanten Blick auf das Serbische als interkulturellen Kommunikationscode. Als Analysebeispiel dient einer der bekanntesten Romane Andrićs überhaupt, nämlich Die Brücke über die Drina (На Дрини ћуйрија). Die Osmanen brachten in die Region den Islam und eine neue Gesellschaftsordnung, der im Roman Rechenschaft getragen wird. Ihre Sprache beeinflusste das gesamte balkanische Sprachareal nachhaltig, weshalb Andrić in seinem Schaffen eine ganze Fülle von Turzismen verwendet (Samardžić trifft einige Aussagen zur wissenschaftlichen Analyse dieser Lexeme. ${ }^{4}$ Saša D. Knežević untersucht

1 KUSTURICA, E., KOVAČEVIĆ, M. (ur.): Značaj srpskog jezika za očuvanje srpskog kulturnog identiteta. I: Ivo Andrić i srpski jezik. Radovi sa naučnog skupa održanog u Andrićgradu 12-13. maja 2018. (= Odjeljenje za srpski jezik. Biblioteka Naučni skupovi; knjiga 1). Višegrad (Andrićgrad): Andrićev institut, 2018, S. 16.

2 Ibidem, S. 27.

3 Ibidem, S. 49.

4 Ibidem, S. 60-64. 
aus linguistischer Perspektive die Einflüsse, die u.a. aus der serbischen Literatur auf die Prosa von Andrić wirken. Vor allem interessieren ihn dabei Volkslegenden sowie mündliche und schriftliche Überlieferungen. ${ }^{5}$ Aleksandar M. Milanović thematisiert in seiner Abhandlung die Einstellung Andrićs zur Belgrader Mundart. Dies ist deshalb aufschlussreich, da Andrić vielen als musterhafter Verwender der Standardsprache gilt (И заиста, ... селектовани йримери из Анgрићевих gела били би рейрезентативни йримери срйскої језика у књижевности, и ту нема ничеїа сйорної.) $)^{6}$ Dieser Umstand hinderte den Schriftsteller jedoch nicht daran, stilistische Färbungen und kolloquiale Formulierungen in seine Texte einzuflechten, die sich größtenteils auch in einem handschriftlich verfassten Wörterbuch der Belgrader Mundart wiederfinden. ${ }^{7}$ Božica D. Knežević stellt den mythopoetischen Raum in Andrićs Prosa vor, wobei sie auf unterschiedliche geographische Objekte mit einer speziellen Funktion eingeht, welche außerordentliche Assoziationen aufwerfen, ${ }^{8}$ während Milanka J. Babić linguistische Charakteristika in der Novelle Brief aus dem fahre 1920 (Писмо из 1920. іоgине) untersucht. Sie hebt die ausgeprägte Endtäuschung über die Erfahrungen aus dem Zweiten Weltkrieg hervor, die sich auf vielfältigen stilistischen und lexikalischen Ebenen bemerkbar machen. ${ }^{9}$ Vjara A. Najdenova hinterfragt im einzigen bulgarischen Text des Bandes die Bedeutung von Interjektionen, die eines der künstlerischen Merkmale in den Женске ириче darstellen. ${ }^{10}$ Im anschließenden Beitrag unterzieht Milka V.Nikolić ausgewählte Werke einer gründlichen stilistischen Analyse und gelangt zu dem Ergebnis, dass Andrić sehr viel an der Originalität einzelner Passagen gelegen ist. ${ }^{11}$ Demgegenüber wertet Biljana B. Mišić die Bedeutung der direkten und der indirekten Rede in der Brücke über die Drina aus. Sie betrachtet dabei den Vokativ, Interjektionen, Partikeln und den Imperativ. ${ }^{12}$ Der nicht-literarische funktionale Stil bei Andrić steht im Mittelpunkt der Untersuchung bei Veselina V.Đurkin, die vor allem darauf verweist, dass stilistische Markierungen nicht nur durch Lexik, sondern auch durch kursive Hervorhebungen oder direkte Rede evoziert werden. ${ }^{13}$ Narrative Gegebenheiten in der Figurencharakteristik werden von Bojo Kovačević ausgewertet, der neben stilistischen Fragen auch den Turzismen Raum

\footnotetext{
5 Ibidem, S. 83-84.

6 Ibidem, S. 88.

7 Ibidem, S. 93-104.

8 Ibidem, S. 111-112.

9 Ibidem, S. 139.

10 Ibidem, S. 147.

11 Ibidem, S. 179.

12 Ibidem, S. 183-190.

13 Ibidem, S. 210-214.
} 
gewährt, ${ }^{14}$ denen bekannterweise ein ausgesprochen wichtiger Platz bei Andrić zukommt, während sich Sanja Đ. Macura in einem weiteren Artikel der Fokalisierung in der Narration widmet - einer Theorie, die mit den Studien von Gérard Genette ihren Lauf nahm und später weiterentwickelt wurde. ${ }^{15}$ Dass aber nicht nur Fragen der Erzähltheorie, sondern auch deren konkrete Gestaltung im Vordergrund steht, vergleicht Ilijana R. Čutura am Beispiel der Romane Die Brücke über die Drina und Wesire und Konsuln (Травничка хроника). Sie analysiert unterschiedliche Typen temporaler Adverbien, die sie als temporal-kausale Interferenzen zwischen den Werken betrachtet. ${ }^{16}$ Ebenso interessant ist es, sich mit der Anordnung von Thema und Rhema bei Andrić zu befassen, eine Aufgabe, der sich Nina S. Milanović annimmt und dabei acht Klassifizierungstypen sowie weitere Untertypen herausstellt. ${ }^{17}$ Dass dieses Thema naheliegt, lässt sich insbesondere am serbischen Originaltitel На Дрини ћуйрија des Romans Die Brücke über die Drina erkennen, der durch die Umstellung von Thema und Rhema bereits Anzeichen auf die kunstvolle Verwendung von Sprache in sich trägt.

Ivo Andrić hatte einen nachhaltigen Einfluss auf die Weltliteratur, für seinen Roman Wesire und Konsuln wurde ihm bekanntlich 1961 der Nobelpreis für Literatur zu Teil. Dass seine Bücher international gelesen wurden, ist letztlich auch dem Umstand zu verdanken, dass das Interesse groß war, sie zu übersetzen. Wie dabei vorgegangen wurde skizziert Maja R. Kujundžić am Beispiel der Passivkonstruktionen, die sie in der englischen Übersetzung der Brücke über die Drina betrachtet. Sie verweist auf zahlreiche Besonderheiten in der englischen Version, die etwa auf die Passivformen zurückgeführt werden, die im Original mit Hilfe des Reflexivums ce ausgedrückt werden. ${ }^{18}$ Der gleiche Roman steht bei Vera M. Vujević Đurić im Mittelpunkt, diesmal aber vor dem Hintergrund eines Vergleichs zwischen der Wiedergabe von Ellipsen in der serbischen und in der englischen Textausgabe. Sie kommt zu folgendem Ergebnis: Све изgвојене и ойисане врсте елийтичних конструкција у срйском језику имале су своје коресйонденте или ирревоне еквиваленте у енілеском. ${ }^{19}$ Mijana Č. Kuburić Macura widmet sich Präpositionalkonstruktionen und der damit zusammenhängenden Kasusrektion, auch hier ist Die Brücke über die Drina eines von drei Kernelementen der Analysen. Vor allem $u$ ūopeg $+N(G e n)$ als Konstruktion mit konzessiver Bedeutung ist in ihren Auswertungen belegt. ${ }^{20}$ Anschließend untersucht

\footnotetext{
14 Ibidem, S. 227.

15 Ibidem, S. 242-243.

16 Ibidem, S. 281.

17 Ibidem, S. 288-296.

18 Ibidem, S. 316-322.

19 Ibidem, S. 350-351.

20 Ibidem, S. 374.
} 
Saša M. Đukić Charakteristika elliptischer Konstruktionen im Roman Der verdammte Hof (Проклета авлија) und stellt heraus, dass es Andrić damit an vielen Stellen im Text gelingt, eine spezielle Intensität des Ausdrucks zu erzielen. ${ }^{21}$ Dem schließt sich eine weitere Analyse zu diesem recht überschaubaren Roman an, diesmal von Svetlana B. Panić zur medialen Deixis im Werk und in dessen Verfilmung. Deiktika sind im Roman häufig, sie dienen insbesondere der aktantialen Kohärenz. ${ }^{22}$ Ein weiterer interessanter Aspekt wird von Sanja M. Kuljanin aufgearbeitet: Sie stellt synthetische und analytische Komparative in Andrićs Werk gegenüber und hält in ihrer Auswertung fest, dass die unterschiedliche Anwendung beider Formen letztlich von Andrićs schöpferischer Extravaganz zeugt. ${ }^{23}$ Sanja Ž. Đurović dokumentiert die Auffälligkeiten der Verben in der Erzählung Mycmaфa Maцар. Hier finden wir eine ausgesprochene Formenvielfalt vor, die Tempora wie etwa Aorist, Imperfekt und Plusquamperfekt einschließt. Dies zeigt, dass die Verwendung mehrerer Präterita und insbesondere die des Aorists in der serbischen Sprache nach wie vor aktuell und funktional berechtigt ist, auch wenn das in erster Linie für die schöne Literatur gilt. $^{24}$ Im letzten Beitrag behandelt Veljko Ž. Brborić die Funktion, die Andrić in Lehrplänen und Lesebüchern in Grund- und Mittelschulen zu Teil wird. Es werden Unterrichtswerke vorgestellt, in denen mit Andrićs Texten gearbeitet wird. ${ }^{25} \mathrm{Nach}$ der Auswertung der Materialien konstatiert er: Анgрић је највећи йисаи наших йростора... Статус Иве Анярића у школском систему Србије и Рейублике Срйске је веома gобар... ${ }^{26}$

Abschließend bleibt festzuhalten, dass im vorliegenden Sammelband sehr vielfältige Problemstellungen miteinander verknüpft werden, die sich mit Ivo Andrić und seinem Werk facettenreich auseinandersetzen. Insgesamt dominieren Studien zur Lexik, zum Stil und zu grammatischen Phänomenen, die in serbischer und bulgarischer Sprache vorgestellt werden. Sicher hätte der Leser davon profitiert, wenn die Anordnung der Einzelbeiträge etwas aufgelockerter wäre. Dies kann jedoch nicht darüber hinwegtäuschen, dass wir es mit einem Werk zu tun haben, welches man aus mehreren Gründen mit Gewinn studieren wird: Die aktuelle Thematik, die Relevanz Andrićs für das kulturelle Bewusstsein der Serben, sein Beitrag zur Weltliteratur, die in den Werken kunstvolle Verwendung von Sprache und die Einbettung der Handlungen in historische, mehrsprachige und multikulturelle Zusammenhänge

21 Ibidem, S. 391.

22 Ibidem, S. 414.

23 Ibidem, S. 437.

24 Ibidem, S. 454.

25 Ibidem, S. 465-471.

26 Ibidem, S. 475. 
werden vorgestellt, diskutiert und wissenschaftlich ausgewertet. Der Band zielt somit auf einen weiträumigen Rezipientenkreis ab, fördert neue Einblicke in die strukturelle Beschaffenheit der Romane und Novellen von Ivo Andrić zu Tage und hebt den Einfluss des Schriftstellers auf die serbische Sprache und Kultur eindrücklich hervor.

Martin Henzelmann

\section{Bibliografie:}

KUSTURICA, E., KOVAČEVIĆ, M. (ur.): Značaj srpskog jezika za očuvanje srpskog kulturnog identiteta. I: Ivo Andrić i srpski jezik. Radovi sa naučnog skupa održanog u Andrićgradu 12-13. maja 2018. (= Odjeljenje za srpski jezik. Biblioteka Naučni skupovi; knjiga 1). Višegrad (Andrićgrad): Andrićev institut, 2018.

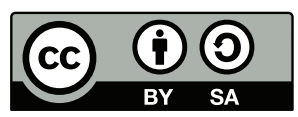

This work can be used in accordance with the Creative Commons BY-SA 4.0 International license terms and conditions (<https://creativecommons.org/licenses/by-sa/4.0/legalcode>). This does not apply to works or elements (such as images or photographs) that are used in the work under a contractual license or exception or limitation to relevant rights.

https://doi.org/10.5817/OS2019-4-8

\section{Kulturní mise latiny v multilingvním prostoru dnešní Ukrajiny}

MYRONOVA, V., HRYCENKO, S., KOROL'OVA, N., KOSIC'KA, O., KOŠČIJ, O., LASTOVEC', M., ŠČERBYNA, M.: Latin in the Multilingual Space of Ukraine in the 15th-18th Centuries. Vychází péčí České asociace slavistů. Vydal Jan Sojnek - Galium, Brno 2019, 126 s. ISBN 978-80-88296-08-9.

Velmi potřebný text vydali klasičtí filologové a medievisté z Kyjeva v rámci svého výzkumu v Brně péčí České asociace slavistů. Jde o klíčové téma dějin východních Slovanů, které spočívá ve změně kulturní a tím dílem i politické orientace. Tato změna proběhla právě v období, jež je obsaženo v titulu práce. Orientace na Byzanc postupně zaniká od jejího úpadku a konečného pádu v 15. století a od té doby začíná sílit vliv germánsko-románské Evropy a středověké a pozdější verze latinského jazyka, jehož prostřednictvím se na teritorium východních Slovanů dostávají dávno 